\title{
LA CIUDAD, EL ESPACIO ENTRE LAS COSAS
}

\author{
Pedro Livni y Gonzalo Carrasco Purull \\ Profesores FARQ Montevideo. Directores Página Vostok
}

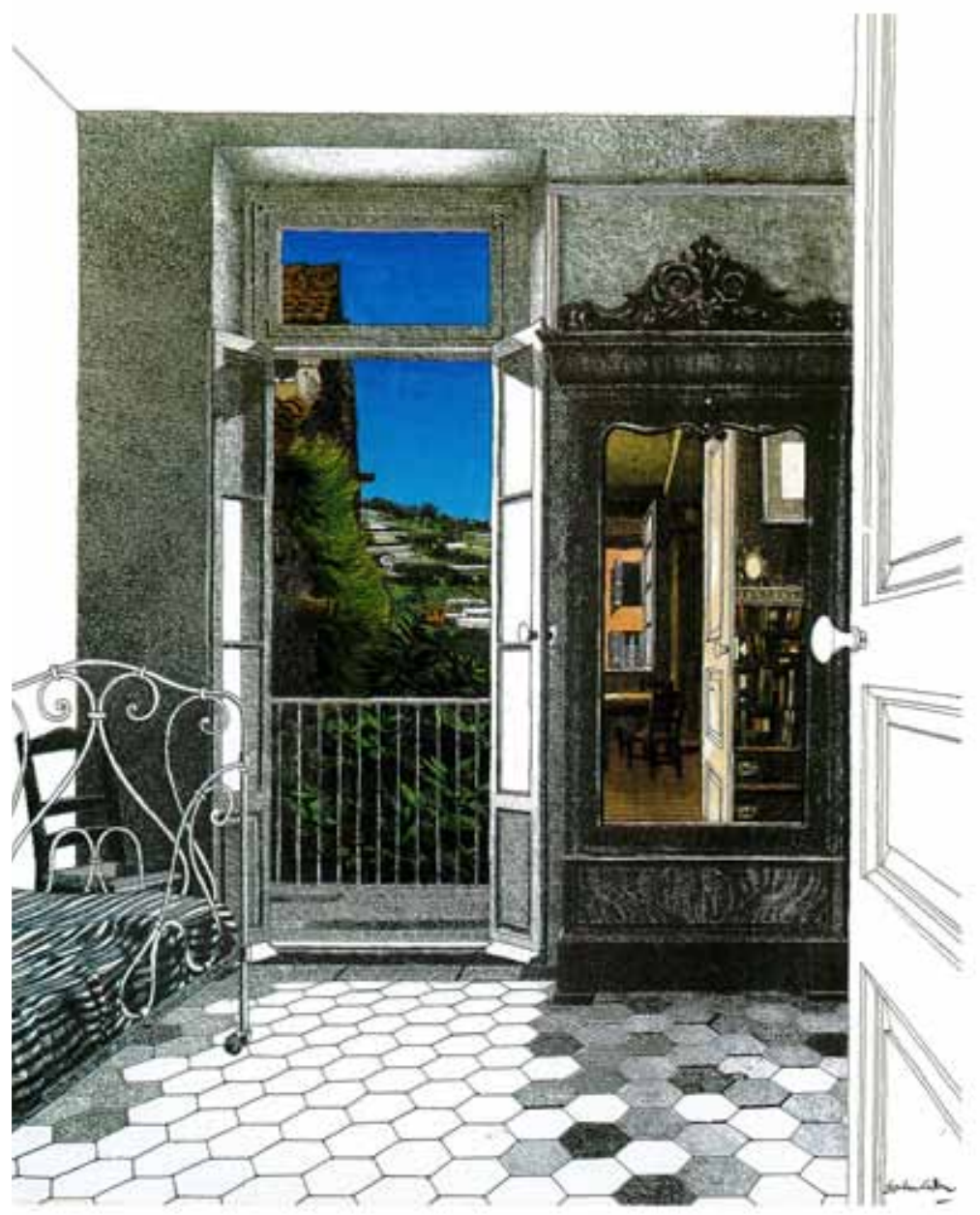

Cuando dos espejos se miran, Satanás hace su truco preferido, y abre aquí, a su manera (como hace su compañero en las miradas de los amantes), la perspectiva al infinito.

Walter Benjamín, El libro de los pasajes

Gordon Cullen : The White Room, de Five Views of Biot, 1974. En: Gosling, David (1996). Gordon Cullen: visions of urban design. London Academy, Londres.

En los setenta, el urbanista, ilustrador y autor del célebre manual de diseño urbano Townsca$p^{1}{ }^{1}$, Gordon Cullen, experimento a su pesar como su vista empeoraba de condición. A la ca- tarata congénita que tenía en uno de sus ojos, se vino a sumar la aparición de un agujero en la retina del hasta ese entonces ojo sano, situación que lo obligó a trabajar y realizar muchas 
de las ilustraciones de este período bajo un constante malestar y con una limitación en su campo de visión que trato de corregir mediante el empleo de unos diminutos binoculares fijos a sus lentes.

Fue precisamente durante estos años en los que Cullen vio menguar su percepción visual, cuando sus dibujos comenzaron a fijar más nítidamente los objetos cotidianos y como estos cualifican nuestros espacios domésticos. Cosas en su acumulación aparentemente azarosa, dan cuenta de la ocupación y activación de estos interiores, condición que Cullen contrapondría con aquella dimensión que resultó ser su campo de acción de por vida como es la ciudad.

Gradación entre las cosas, la habitación y la ciudad de la cual Cullen dejo registro en 1973 en una pintura de reducido formato, donde se muestra la entrada de una casa pequeña, vista a través de una serie de espacios. Vista que estaba acompañada por la siguiente descripción: La yuxtaposición del exterior y el interior. En el espejo se puede observar los cálidos y útiles objetos domésticos. Contiene al ambiente rancio a humo de cigarro, la descolorida tapicería de seda, el reloj poniendo a prueba al silencio y el clic del medidor del gas. Afuera, silenciados a través del espesor de la puerta, las huellas y fragmentos de una conversación al aire libre puede ser escuchada. Pero cerrada por fuera, como puede, el mensaje fatal llega. Un único momento de hormigueante ambivalencia ${ }^{2}$.

Un verdadero ejercicio de écfrasis o representación verbal de una representación visual, a la cual Gordon Cullen regreso en su poema Ambivalencia: el correo matutino, en donde nuevamente la arquitectura queda situada entre estos dos extremos, como es un interior lleno de cosas que lo caracterizan, dando cuenta de su reciente ocupación y por otro, el exterior de una ciudad que está comenzando sus actividades diarias:

Cada mañana el dueño de la casa / camina hacia la puerta principal / para verificar la temperatura emocional del día. Sorpresa, esperanza diferida y problemas / yacen sin rótulo entre / la persuasión maliciosa, el vacío y la ternura. Una mañana el salió hacia la temprana luz / como la realización de su posición ocultando su propósito. En el espejo el mira la cálida, confortable domesticidad / de la desteñida tapicería de seda / en el familia ambiente del humo del cigarro, / el reloj probando al tiempo a través de la gravedad y la blanca luminosidad / que baja tamizada por la escalera / por debajo de la cual el medido gas hace clic sobre su sencilla repisa vino tinto. Afuera, silenciado a través del espesor de la puerta remachada / las huellas y fragmentos de unaconversación/crecenysedesvanecen al aire libre / Por primera vez su mente estáfuertemente focalizada/ en dos deseos separadosy contrarios: / quedarse o salir fuera.

El conoce su rutina pero por un hormigueante instante / dio paso a un incansable entusiasmo $\sin$ fin.../luego el comenzó a abrir sus cartas ${ }^{3}$.

Una detención en las cosas y su capacidad de establecer toda una serie de gradaciones entre las cualidades presentes en los espacios interiores y exteriores, que Cullen fijó visualmente justamente en el dibujo homónimo al poema. En donde y desde una vista frontal dividida por la mitad, se muestra a la derecha un espejo que devuelve la mirada hacia atrás de la escena, en una perspectiva que simultáneamente da a una puerta que parece dar a la cocina y al jardín trasero, y por otra parte, a una habitación situada en un nivel intermedio de la escalera de cuyo 
interior solo se muestra un reloj de péndulo, un sillón y una pared con un papel mural de rayas verticales.

Asimismo, bajo el tramo que sigue subiendo de la escalera, Cullen agrega una tercera perspectiva reflejada en el espejo que es otro espejo, cuyo reflejo devuelve la imagen esta vez del suelo de la habitación y la alfombrilla frente a la puerta. Por el contrario, en la mitad izquierda de Ambivalency, no hallamos esta vez la vista hacia el espacio interior detrás del observador, sino que dos fragmentos de aquello que acontece fuera de la escena. Dos ventanas, una ubicada en la misma puerta y cuya vista aparece velada por una pequeña cortina de visillos, y una superior sobre el dintel de la puerta, ofrecen evidencias de la arquitectura de la ciudad fuera de la habitación.

En un ejercicio que no solo recuerda en sus medios a los espejos de las pinturas de Velázquez o de Van Eyck, sino que también a esa simultaneidad entre interior y exterior, entre habitación y ciudad que Hitchcock monta en la secuencia de inicio de su película Rear Window (1954). Mirada donde las cosas, los recintos interiores y la ciudad son presentadas con igual importancia, como un sistema de objetos que en su conjunto cualifican aquellos ambientes en los que se despliega la vida cotidiana y que resulta ser el ámbito propio de la arquitectura.

Aproximación al que regresaría Cullen el año siguiente con The White Room, dibujo que pertenecía a su serie Five Views of Biot y en el que también recurre al medio del espejo para ofrecer una vista hacia el espacio detrás de la escena, haciendo que el ojo cruce la crujía del departamento hasta alcanzar a las ventanas de la fachada del edificio que se levanta detrás. Pero en este caso la mitad izquierda de la escena no ofrece tan solo fragmentos de ciudad, sino que también los de un paisaje formado por una serie de plantaciones y bosques que ascienden por una suave colina.

Nuevamente lo lejano, lo próximo y lo inmediato son colisionados en un solo golpe de vista, homologando tanto los objetos que se acumulan en el cuarto -cama, silla, escritorio, librero, armario- con la propia arquitectura de la habitación, como con la dimensión urbana y del paisaje que las dos ventanas de la escena ofrecen. Simultaneidad que permite la visión a través de un espejo que resulta sumamente urbana, tal como lo constató Walter Benjamín en su Das Passagen-Werk, en donde señaló que: Cuando dos espejos se miran, Satanás hace su truco preferido, y abre aquí, a su manera (como hace su compañero en las miradas de los amantes), la perspectiva al infinito. Ya sea divina o satánicamente: París tiene pasión por las perspectivas especulares. El Arco del Triunfo, el Sacré Coeur, incluso el Panteón, aparecen de lejos como imágenes suspendidas a media altura, entreabriendo arquitectónicamente el espejismo ${ }^{4}$.

En una mirada que no solo resulta coherente con el extremo cuidado que Cullen puso en las diversas gradaciones que existen entre las cosas que cualificaban el espacio de las escenas urbanas que aparecen en Townscapes, sino que también con su propia práctica profesional como diseñador urbano. En especial con el proyecto para la localidad de Maryculter (Aberdeen, Escocia del Norte) que desarrolla en 1974, casi en los mismos meses cuando realiza los dibujos anteriormente mencionados.

Un proyecto en el que esta simultaneidad entre habitación y ciudad se vuelve explícita en el concepto de Hábitat para casas, a través del cual Cullen justamente subraya la deficita- 
ria condición del diseño de los suburbios, en donde cada casa aparece aislada, sin ningún tipo de nexo entre ellas. Una situación que la hace equivalente a no tener morada, fue así que para Cullen: La gente vive en casas, pero, ¿Dónde viven las casas? Si son personas sin hogar [homeless], luego todo lo que nos queda, es el típico suburbio, sin fin ni carácter ${ }^{5}$.

Estableciendo de esta manera un acercamiento al problema urbano en el que los edificios no aparecen como cuerpos aislados, sino que por el contrario, fuertemente relacionados entre si por toda una serie de objetos que llenan el espacio entre ellos. Dando forma a un sistema de gradaciones donde la habitación se vuelve zaguán, este a su vez se troca en escalera, la cual lleva a un pequeño mercado, que rodea una galería, que termina en un mirador desde el cual se tiene dominio de un parque cuyos límites dan inicio a nuevas gradaciones.

En una aproximación a través de la cual el propio Cullen complejiza el problema de la continuidad espacial entre los interiores domésticos y el espacio entre los cuerpos edificados que esbozo tanto en sus ilustraciones para Architectural Review, su diseño para un pocket-garden en el marco del Festival of Britain de 1951 (un hibrido entre habitación interior y terraza exterior) y sobre todo en sus dibujos de interiores incluidos en el estudio de 1962 para la Lavanburg Foundation de Nueva York. En los que bajo el titulo de los Commons, se mostraba la vista al interior de una sala de estar de un edificio habitacional, dejando sin resolver la continuidad entre la abarrotada vida interior y la soledad de las torres de viviendas que sobre un gran parque modernista se lograba divisar a través de un amplio ventanal ubicado al fondo de la escena.
Una falta de relación entre las diversas partes que construyen la ciudad, tras la cual había una aproximación a la forma urbana entendida más que nada como el despliegue de toda una serie de obras singulares fuertemente autónomas. Algo que en el caso de las ideas urbanas de Le Corbusier ha sido explicado por Jean-Louis Cohen $^{6}$ a partir de la fuerte impresión que dejo en él, el Antiquae Urbis Imago, plano que de la ciudad de Roma realizó Pirro Ligorio en 1561. Documento del cual Le Corbusier hizo una versión hacia 1915 que posteriormente incluiría en Vers une architecture, en donde volvió aún más radical la autonomía y carácter aislado de la arquitectura dibujada por el arquitecto italiano. Y es que esta tal vez fue la principal característica de la Roma representada por Ligorio, una que tal como ha advertido Pier Vittorio Aureli aparecía como una ciudad casi sin calles y poblada de objetos: diferentes composiciones de cúpulas, pirámides, cubiertas apuntadas, obeliscos, anfiteatros, exedras, pórticos y circos $^{7}$.

Dejando así al espacio entre las arquitecturas como un interregno aparentemente neutro, únicamente determinado por el trazado dejado por la disposición de los edificios. Estado de vacancia de unos espacios a la espera de ser llenados, que en el caso de la versión del plano hecha por Le Corbusier, se amplían las distancias entre los edificios, convirtiendo a Roma en un conjunto de objetos arquitectónicos dispuestos sobre una gran planicie indeterminada. Y fue precisamente esta indefinición sobre la cualidad del espacio entre las cosas la posición que primó en las ciudades del siglo XX.

Un acento puesto en las cosas por sobre el espacio entre ellas del cual dan cuenta la serie de fotografías que de Brasilia realizara por René Burri apenas esta estuvo inaugurada. 
Pero también desde posiciones supuestamente críticas frente a la ciudad modernista, como fueron las imágenes de ciudades-palimpsesto que Colin Rowe y Fred Koetter incluyeron en Collage City $(1978)^{8}$, en las que la ciudad se reduce a una serie de formas que se imbrican y colisionan sobre un neutro e indefinido espacio dejado en blanco.

Sin embargo la visión fuertemente autónoma dada por Ligorio en su obra, tuvo más matices en el caso de Andrea Palladio. Quien en sus I Quattro Libri dell 'Architettura (1570) expone las competencias de la arquitectura divididos entre los edificios privados (libros I y II) y los de carácter público que de manera más decisiva dan forma a la ciudad (libros III y IV). Una gradación de la cual Palladio explica en el proemio del libro III: Por lo tanto, yo, en este tercer libro, al poner los dibujos de aquellos edificios que en él se contienen, seguiré este orden: pondré primero los de los caminos y los puentes, como parte de la arquitectura que pertenece al ornamento de las ciudades y provincias, y sirve a la comodidad universal de todos los hombres [...] Después trataré de las plazas (según nos enseña Vitruvio que las hacían los griegos y latinos), de los lugares que se deben hacer alrededor de las plazas, y porque entre éstos es de muy digna consideración el lugar donde los jueces ejercen la justicia, llamado por los antiguos basílica, se pondrán particularmente dibujos de éstas [...] Y es justísima razón que los habitantes de una región, estando dispersos en muchos y pequeños lugares, se unan en ciudades, por lo que los antiguos griegos hicieron en sus ciudades (como cuenta Vitruvio) algunos edificios, que llamaron palestras y xustós, en los que se reunían los filósofos a tratar de las ciencias y donde los jóvenes se ejercitaban cada día [...] y así se habrá terminado este libro tercero, después del cual seguirá el de los templos, pertenecientes a la religión, sin la que es imposible que se mantenga ninguna civilización ${ }^{9}$.

Una ciudad por lo tanto construida a partir de la reunión de caminos, puentes, prisiones, basílicas, palestras, templos, arcos de triunfo, anfiteatros, acueductos, termas, fortificaciones, puertos, así como viviendas. En un orden que dice mucho del carácter cívico que Sansovino imprimió en sus intervenciones sobre San Marcos y del cual queda registrado en la importancia que Palladio le otorga a los elementos que median entre las habitaciones y el espacio público, como logias y entradas.

Lugares que son como sitios públicos y los que en el caso de las entradas, sirven para estar los que esperan que el dueño salga de casa, para saludarlo y negociar con él, y es lo primero (además de las logias) que se ofrece a quien entra en la casa ${ }^{10}$. Pero también este carácter público de la arquitectura Palladio la proyecta hacia el interior de las salas, las que sirven para fiestas, representaciones de comedias, bodas y solaces semejantes. Por esta razón, estos lugares deben ser mucho mayores que los otros y deben tener gran capacidad, a fin de que mucha gente pueda estar cómodamente y vea lo que se haga ${ }^{11}$.

Por lo tanto si se observa la estructura general de los Quattro Libri, se tiene un gradual avance desde el ámbito de lo privado a lo público, desde el campo (la villa) a la ciudad, que resulta similar al decir, de la casa individual a la casa de todos. Enfoque cuyo extremo resulta ser nada menos que las habitaciones, aspecto que para Palladio resulta fundamental en la configuración total del edificio, de su estructura, así como de sus proporciones ${ }^{12}$.

No obstante, la visión de la ciudad de Ligorrio construida a partir de cuerpos autónomos pareció prevalecer. Una opinión que 
fue compartida por el precursor del urbanismo moderno, Camillo Sitte, quien en su obra La construcción de ciudades según principios artísticos (1889), se preguntaba de que: Es muy curioso observar que en la época moderna la historia artística de la urbanización no va al unísono con la de la arquitectura y demás artes plásticas. Obstinase en seguir su camino indiferente a todo cuanto pasa a su lado. Durante el Renacimiento y el Barroco ya sorprendía esta disparidad [...] se erigieron basílicas del tipo de las primitivas iglesias, propileos helénicos, catedrales góticas...pero ¿dónde dejaronse las plazas trasunto del ágora, del foro, de la plaza mercado, de la acrópolis?...Nadie pensaba en esto ${ }^{13}$.

Un énfasis en los edificios antes que en el espacio entre ellos, en el que se profundizó una vez que la calle al absorber todo un conjunto de nuevos sistemas tecnológicos -sanitarios, energéticos, de comunicaciones y de transporte mecanizado- se convirtió en una infraestructura más, dejando al espacio público como una competencia más de las ingenierías. Nuevo escenario del que dio cuenta el propio Sitte cuando advertía que: Nadie se preocupa de la urbanización como arte: considérasela solo como problema técnico, y cuando el efecto artístico no responde a nuestras esperanzas, quedamos sorprendidos y perplejos...Pero a pesar de ello, en la próxima empresa se trata todo nuevamente desde el mismo punto de vista, como si fuese un trazado de ferrocarriles en que se hace abstracción del sentimiento ${ }^{14}$.

De ahí que Sitte propuso abandonar este ensimismamiento que presentaba la forma arquitectónica para pensar en términos de conjunto y no en solares individuales. Para esto describió la forma urbana a partir de un registro en el que destacara antes que nada, el espa- cio visible y vacío entre las masas edificadas ${ }^{15}$, con fin de poder hacer evidente cual resulta ser el principal campo de trabajo del urbanista: el espacio entre las cosas.

Un enfoque que tal como ha advertido George R. Collins, pertenece a una larga tradición pictórica, que se vio potenciado en el siglo XVIII con las vedutas de paisajes pintorescos, así como en las imágenes urbanas de un Pugin o de las innumerables ilustraciones que acompañaban los libros de viajes del siglo XIX, de las cuales dio cuenta el propio Sitte al inicio de su libro cuando describe aquellos gratos recuerdos de viaje integran nuestros más beloos sueños. Hermosas imágenes de ciudades, monumentos, plazas, panoramas, pasan ante nuestra alma, y otra vez gozamos de aquello a cuyo lado fuimos tan felices al detenernos ${ }^{16}$.

Una visión contextualista del fenómeno urbano, al que se le dio el nombre de Townscape en el artículo Exterior Furnishing or Sharawaggi: The Art of Making Urban Landscape publicado en el número de enero de 1944 de la Architectural Review. Enfoque al que en la década de los cincuenta se sumaron trabajos tales como los de James J. Gibson ${ }^{17}$, Steen Eiler Rasmussen ${ }^{18}$ y George Everard Kidder Smith ${ }^{19}$, y que a través de la primera edición del Townscape de Gordon Cullen a inicios de los sesenta se dio a conocer mundialmente en las escuelas de arquitectura y los despachos de los urbanistas. Haciendo de la percepción de los entornos urbanos un tema que fue incorporado en obras claves de esa década, como fueron las de Kevin Lynch ${ }^{20}$, Jane Jacobs $^{21}$, Edward T. Hall ${ }^{22}$ y Edmund Bacon ${ }^{23}$. Pero también en los proyectos desarrollados en la Cornell University School of Architecture en los sesenta, como en los dibujos de un declarado seguidor de Sitte como fue Leon Krier. 
Pero, a diferencia de estos trabajos, el de Cullen no solo muestra pintorescas escenas urbanas y como los diversos tipos de edificios desde su propia individualidad pueden establecer una idea de conjunto, sino que sobre todo destacan por presentar entornos siempre llenos de vida urbana. La cual no aparece tan solo como la distribución más o menos variada de personas y mobiliario, sino como un sistema de diversos tipos de gradaciones. De ahí la relevancia que tienen los dibujos del período de Ambivalency y The White Room antes mencionados, en los que esta gradación no se limita tan solo a los exteriores -la caja vacía de Sitte- sino que arranca ya desde los interiores, ampliando así los límites del espacio urbano, o lo que es lo mismo, domesticándolo.

Y es que las imágenes urbanas de Cullen pueden leerse también desde esta clave, como habitaciones exteriores, en donde la caracterización de estos espacios no queda únicamente relegada a los elementos estrictamente arquitectónicos, sino que también a los no arquitectónicos como resultan ser los elementos vegetales, los diversos niveles del suelo, toldos y otros componentes del mobiliario urbano. Un valor dado a los objetos que aparecen en estas escenas urbanas que resulta coherente con el rol que adquieren las cosas cotidianas en el poema Ambivalency de Cullen, en el que todos estos cálidos y útiles objetos domésticos son percibidos de manera equivalente a las señas que del espacio urbano se tiene desde este interior.

Espacio que se anuncia silenciado por la puerta cerrada, como las huellas y fragmentos de una conversación, que crece y se desvanece. Un acento en la característica fragmentaria y evocativa que tienen los objetos, que coincide con la particular lectura que Walter Benjamín hizo del interior de un típico departamento burgués del Paris de la época de Luis Felipe. En el que: El interior no sólo es el universo del hombre privado, sino que también es su estuche. Habitar es dejar huellas. El interior las acentúa. Se imaginan en gran cantidad fundas y cobertores, forros $y$ estuches en los que se imprimen las huellas de los objetos de uso diario. También se imprimen en el interior las huellas de quien lo habita. Surgen las historias de detectives que persiguen esas huellas. Tanto la "Filosofía del mobiliario" como sus cuentos de detectives acreditan a Poe como el primer fisonomista del interior. Los criminales de las primeras novelas detectivescas no son ni aristócratas ni “apaches", sino burgueses, gentes privadas ${ }^{24}$.

Huellas, pistas, vestigios, fijados a las cosas y que dan cuenta del paso de quien mora los interiores de la arquitectura. Objetos que en su acumulación llenan el espacio de una red de relaciones, memoria y sentido, que recuerdan interiores célebres por constituirse en verdaderas estratificaciones de los deseos y obsesiones de sus dueños, como son las habitaciones de la residencia del arquitecto John Soane en el número 13 de Lincoln's Inn Fields. En donde a la manera de una Wonder Chambers inglesa (Wunderkammern) del tipo de las artificialia, o sea aquellas que se caracterizaban por la exhibición de obras de arte y antigüedades, se despliegan objetos de toda clase, incluyendo fragmentos de cornisas, capiteles y frontones clásicos, así como copias de mármoles romanos, jarrones italianos y chinos, así como vasijas y piezas egipcias, configurando recintos en los que el espacio se vuelve inseparable de su contenido, dando forma a verdaderos paisajes interiores generados por la acumulación del coleccionista. Una condición compartida también por otro interior, como fue el pequeño 
departamento que el artista surrealista André Bretón arrendó entre 1922 y 1966 en el 42 de la rue Fontaine en el distrito de Pigalle en París. Lugar que fue el escenario de la reunión de más de 5300 objetos, que entre pinturas, dibujos, esculturas, fotografías, libros, catálogos, diarios, manuscritos, fósiles, conchas marinas y obras arte popular polinésico y americano, fueron llenando año tras año los muros, repisas, dinteles de puertas y cualquier espacio que apareciera disponible.

Una colección de la cual nunca Breton se quiso deshacer y que únicamente se vio menguar en aquellas ocasiones cuando la falta de recursos lo obligaba a vender alguna de sus piezas para pagar la cuenta de la luz o del agua potable. Dando forma a un escenario fuertemente ligado al sujeto que lo ocupa, del cual los objetos son sus huellas y vestigios. Un tipo de espacio que resulta muy similar al interior de alguien tan cercano al mismo Breton, como era el despacho de Sigmund Freud en Viena.

Un lugar de trabajo pero también de estratificación de una serie de objetos cotidianos, libros, como también de fetiches africanos, figuras de animales y vasijas, que dan cuenta de un tipo de espacio que fue caracterizado por Benjamín como: El interior es el lugar de refugio del arte. El coleccionista es el verdadero inquilino del interior. Hace asunto suyo transfigurar las cosas. Le cae en suerte la tarea de Sísifo de quitarle a las cosas, poseyéndolas, su carácter de mercancía. Pero les presta únicamente el valor de su afición en lugar del valor de uso. El coleccionista sueña con un mundo lejano y pasado, que además es un mundo mejor en el que los hombres están tan desprovistos de lo que necesitan como en el de cada día, pero en cambio las cosas si están libres en el de la servidumbre de ser útiles ${ }^{25}$.
Pero este énfasis en la capacidad que tienen los objetos cotidianos de tender relaciones entre ellos y dar evidencia de la ocupación de los espacios, también fue abordado por Le Corbusier. Quien ya desde su regreso desde Berlín a la Chaux-de-Fonds en 1911 se anunciaba como arquitecto consultor en todas las materias relacionadas a la decoración ${ }^{26}$, años en los que todavía diseñaba el mobiliario y los interiores de los proyectos para las familias Ditisheim, Schwob y Levaillant de acuerdo a los patrones Biedermeier que popularizaran Mabes y Adolf Loos. Situación que cambiaría en la década de los veinte, principalmente a través de sus trabajos en colaboración con Charlotte Perriand y Pierre Jeanneret para la Villa Church (1927-29) y sobre todo en el Salon d Automme (1929). Circunstancia en la que la cuidadosa disposición de mesas, sillas, chaiselongue, butacas y boudouir son los elementos que no solo dan cuenta de una nueva manera de entender las relaciones entre los objetos del espacio doméstico moderno y las experiencias asociadas a la utilización de nuevos materiales, sino que también de nuevas formas de ocupación. De la cual quedó registro en los objetos cotidianos como utensilios de cocina, pipas, ceniceros, lápices o libros abiertos dispuestos sobre mesas y repisas, dando cuenta de un hipotético dueño de casa que habitaba la exhibición y que repentinamente había abandonado la escena.

Cuidado en el poder evocativo de los objetos cotidianos que se tradujo también en el protagonismo que tuvieron estos en las naturalezas muertas que dominaron gran parte de su obra pictórica. Construcciones en las que el estatus dado a las cosas oscilo entre el constituirse como meros signos, a denotar objetos-tipo o simplemente objetos encontrados, reunidos casi siempre sobre una mesa. 
Tal como fue el caso de su Naturaleza muerta con tabla para cortar (1928), en la que sobre una mesa se agrupan un pocillo de porcelana, dos cuchillos, un uslero, una tabla para cortar, algunos huevos y una hoja de periódico arrugada. Objetos que en su reunión aparentemente fortuita, dan cuenta de un usuario que se halla fuera del cuadro. Un recurso que había utilizado ya en su temprana El cuenco rojo (1919), en donde comparece la abstracción de un cubo de madera con la evidencia del trabajo de un diseñador fijado a el papel secante, el plano enrollado, la pipa y la taza de café. En un juego de huellas que obligan al observador a ir conectando de manera similar al proceder del Sherlock de Doyle o el Dupin de Poe, las pruebas de un sujeto ausente ${ }^{27}$.

Una estrategia que ya Heinrich Tessenow había empleado en las ilustraciones de interiores que aparecen en Hausbau und Dergleichen (1916) y que Le Corbusier utilizó ampliamente tanto en las series de croquis y fotografías de acompañaban los proyectos que figuran en los volúmenes de su Oeuvré. Imágenes que tal como lo ha analizado Beatriz Colomina ${ }^{28}$, constituían verdaderas mise-en-scène, tal como aparecen en las fotografías del comedor de la Villa Le Lac (1924-25), la cocina de la Villa Stein (1927) o el estar de la Casa de fin de semana (1934-35). Sin embargo en donde comparecen simultáneamente las relaciones de sentido y memoria que desencadenan los objetos cotidianos a los cuales se fija la vida doméstica y la ciudad, fue en el proyecto para el departamento y jardín-terraza que Le Corbusier diseñó para Charles de Beistegui (1929-31).

En el que y tal como ha señalado Tafuri, el panorama parisino de la Torre Eiffel y el Arco del Triunfo desde esta habitación a cielo abierto (chambre à ciel ouvert), en que el espacio aparentemente vació es llenado por la capacidad evocativa de una serie de objetos de reacción poética (objects à réaction poétique). Objetos que en su condición poética de una domesticidad desplazada son capaces de reconciliar ambas escalas $^{29}$, dando a elementos tales como sillas, chimenea, pintura, repisa, reloj, cuadro y espejo, un estatus similar en su capacidad evocativa de las conchas, caparazones de cangrejo, piñas, guijarros y huesos de todos tamaños y formas que Le Corbusier atesoraba formando verdaderos gabinetes de curiosidades que empleaba indistintamente como fundamento para sus arquitecturas como en las formas de sus proyectos urbanos.

De este poder que las cosas cotidianas poseen para fijar los modos y actividades humanas a las habitaciones era muy consciente Le Corbusier, tal como lo dejo en claro en 1943 en su Mensaje a los estudiantes de arquitectura señalando que: El urbanismo surgió así una vez más desde lo profundo de las edades, teniendo como misión colocar una civilización "en sus muebles" (...) me he inclinado muy particularmente sobre el problema: vivienda-urbanismo, binomio indisoluble. Lo he explorado según una regla adquirida fuera de las escuelas: de adentro hacia afuera, regla que me parece ser la ley de la naturaleza al igual que la arquitectura. Ilustremos: El hombre (ese hombre que siempre está delante de mí, con sus dimensiones, sus sentidos y su afectividad) está sentado junto a su mesa; sus ojos se posan sobre los objetos que lo rodean: muebles, alfombras, cortinas, cuadros o fotografías y muchos otros objetos a los cuales asigna importancia. Una lámpara lo alumbra o el sol que penetra por una ventana, separando la sombra de la luz, oponiendo estos dos pesados extremos de reacción 
sobre lo físico y lo psíquico: lo claro y lo oscuro. Las paredes de una habitación se ciernen sobre ély sobre sus arreglos. Nuestro hombre se pone de pie, camina, abandona la habitación, pasa a otro sitio, a cualquier sitio. Helo aquí abriendo la puerta de la vivienda, saliendo de su casa. Aún está en su casa: un corredor, escaleras, ascensor... Helo aquí en la calle. ¿Cómo es este exterior? ¿Hostil o acogedor? ¿Seguro o peligroso? El hombre está en las calles de la ciudad y helo aquí, después de ciertos actos sucesivos, fuera de la ciudad, en el campo. La arquitectura no lo ha abandonado ni un instante: muebles, habitación, luz solar o artificial, respiración y temperatura, disposición y servicios de su vivienda, la vivienda, la calle; el sitio urbano; la ciudad; la palpitación de la ciudad; el campo, sus caminos, sus puentes, sus casas, verde y cielo, naturaleza [...] Arquitectura es todo: su silla y su mesa, sus muros y sus habitaciones, su escalera o su ascensor, su calle, su ciudad ${ }^{30}$.

Sin embargo a este hombre que tan amorosamente trata Le Corbusier lo terminaría dejando como muchos de sus colegas modernistas parado en el descansillo de la puerta de acceso frente a un espacio urbano desolado, absolutamente vacio. En el que la domesticidad es lo que queda a su espalda, una vez que se cierra la puerta tras sí. Según Le Corbusier, la arquitectura es un ente totalizador que lo seguiría a todas partes, aun cuando ha abandonado su casa. Pero los objetos que lo acompañan fuera ya carecen de su poder de evocación de la reciente ocupación o presencia de alguien que ha estado morando allí, sino que figuran tan solo como meras formas que actúan antes que nada como metáforas, haciendo de la arquitectura un juego de relaciones poéticas.

Porque no hay nada más distante en cuanto domesticidad que la compleja red de aso- ciaciones simbólicas, de memoria, usos y costumbres desplegada por los objetos cotidianos que se observa en las fotografías del interior del propio departamento-estudio que el arquitecto tenía en el número 24 de la rue Nungesser-et-Coli en Paris (Immeuble Molitor, 1931-1934) que el desierto al que son expulsados los habitantes de sus Unité d’habitation de Marsella, Berlín o Nantes, o peor aún, a las inmensas distancias que separan los edificios de Chandigarh.

Un problema que fue advertido por Colin Rowe y Fred Koetter en su célebre comparación entre el espacio público de la Unité d habitation de Marsella y los Uffizi de Vasari en Florencia ${ }^{31}$. No obstante, aún en este análisis el espacio entre los edificios adolece de aparecer únicamente como un espacio vacante, a la espera de ser llenado de alguna manera. De ahí el valor de la mirada ambivalente detrás de las ilustraciones de Gordon Cullen, una aproximación que se hace hoy en día más urgente que nunca, una vez que el espacio público ya no sólo sigue siendo un interregno que oscila entre constituirse como un mero residuo espacial entre las líneas oficiales y el ámbito específicamente técnico del ingeniero de transportes o sanitario.

Sino que además, se ha convertido en un lugar cada vez más sujeto de los intereses de mercado, privatizándolo, confiriéndole modos y prácticas de control, y transformándolo a la postre en un territorio en donde la domesticidad ha sido definitivamente excluida. En lo que según Slavoj Zizek ${ }^{32}$, se ha convertido en un remedo entre líneas de propiedad, donde la contemporánea obsesión por las pieles arquitectónicas vendría a representar más bien las barreras y límites donde comienza y termina la propiedad privada y los modos asociados a estos espacios. 
La necesidad de superar esta situación y de pensar la ciudad no tanto desde la iconicidad de los edificios sino que desde el espacio entre ellos, ha sido una apuesta llevada adelante por arquitectos que han planteado el límite entre lo público y lo privado no tanto desde el respeto irrestricto a una línea oficial, sino que desde la gradación entre estas dos esferas. En una secuencia de umbrales donde puerta, jardín, vereda, la arborización, la vía y nuevamente la vereda, el jardín y la puerta, surgen como dimensiones integradas a toda arquitectura urbana.

Perspectiva que Aldo van Eyck reunió bajo el concepto de umbral en Otterlo en 1959: Hay una cosa más que ha estado creciendo en mi cabeza desde que los Smithson pronunciaran la palabra "umbral" en Aix. No me ha dejado desde entonces. He estado reflexionando sobre ello, ampliando el significado tan lejos como podía estirarlo. He ido incluso tan lejos como para identificarlo como un símbolo que nos remite a la arquitectura como tal y que ésta debería conquistar. Establecer "lo intermedio" es reconciliar polaridades opuestas. Proporcionar el lugar donde puedan intercambiarse y restableceréis el fenómeno dual original ${ }^{33}$.

Una gradación de cuya necesidad José Fernandez-Llebrez da cuenta en su tesis doctoral, apoyándose también en el enfoque de umbral propuesto por Van Eyck, en el que: $A$ diferencia de los Smithson, más que limitarlo prácticamente a la transición entre la casa y la calle, Van Eyck extiende el significado de umbral (lo intermedio) hasta abarcar cualquier relación importante entre persona y objeto o entre persona y persona. Como es evidente, "esta relación entre individuos no debe ser situada en su interior sino literalmente entre ellos". De ahí la trascendencia de lo interme- dio como ámbito donde se relacionan dos realidades independientes - o incluso contrapuestas - pero condenadas a complementarse. Y de ahí también la importancia de que la arquitectura (o el urbanismo) con el objeto de cultivar su dimensión humana preste una especial atención a esos espacios intermedios donde las personas se encuentran y se relacionan ${ }^{34}$.

Atención que se fija a los objetos que dan cuenta y son evidencia de la ocupación de los espacios. En los que y tal como apuntaba Benjamín, se fija la memoria y se acumulan las pistas y huellas de quienes son sus moradores. Una perspectiva en la que los edificios más que piezas individuales, aisladas en su ensimismamiento icónico, se constituyen como piezas de un conjunto pleno de sentido. Un objetivo para el cual el espacio público no se considere simplemente como algo dado, sino que algo que tiene que ser construido y domesticado.

En donde el exterior pueda aparecer provisto de una cualidad similar a la que se encuentra al interior de una habitación. Giro que obliga a pensar en el espacio entre las cosas como una extensión de lo doméstico, realidad ante la cual reviste suma importancia los distintos niveles de aproximación. Tal como el mismo Cullen fijo en su serie de dibujos que realizó en 1965 para Architectural Review del edificio del Economist de los Smithson. En los que el conjunto va apareciendo en sucesivos planos y en donde la ciudad funciona al mismo tiempo como complemento y escenario para una arquitectura que funciona desde diversas escalas y horizontes. Haciendo del espacio entre las cosas aquella dimensión desde la cual la ciudad puede volver a ser recuperada por la arquitectura. 


\section{NOTAS}

1 Cullen, Gordon (1974), El paisaje urbano: tratado de estética urbanística. Blume, Barcelona.

2 Citado en: Gosling, David (1996). Gordon Cullen: visions of urban design. London Academy, Londres. Pág. 108.

3 Gosling, Op. Cit., pp. 108-109.

4 Benjamin, Walter (2009). El libro de los pasajes. Akal, Madrid. Pág. 552.

5 Gosling, Op. Cit., p.. 102.

6 Cohen, Jean-Louis (2013). Le Corbusier: An Atlas of Modern Landscapes. Museum of Modern Art, Nueva York.

7 Aurelli, Pier Vittorio (2011). The possibility of an absolute architecture. The MIT Press, Cambridge, Mass.

8 Rowe, Colin; Fred Koetter (1979). Ciudad Collage. Gustavo Gili, Barcelona.

9 Palladio, Andrea (1988). Los cuatro libros de la arquitectura. Akal, Madrid. Págs. 264-265.

10 Paladio, Op, Cit, p. 118.

11 Palladio, Op. Cit., pp. 118-119.

12 Las habitaciones más hermosas y proporcionadas, y que mejor salen, son de siete tipos: se harán, pues: redondas (raramente) o cuadradas; o bien, su longitud será la línea diagonal del cuadrado de la anchura, o de un cuadrado y un tercio, o de un cuadrado y medio, o de un cuadrado y dos tercios, o de dos cuadrados. Palladio, Op. Cit., p. 119.

13 Colins, George R.; Christiane C. Collins (1980). Camillo Sitte y el nacimiento del urbanismo moderno / Construcción de ciudades según principios artísticos. Gustavo Gili, Barcelona. Págs. 101-102.

14 Collins, Op. Cit., p. 103.

15 Hoy se construye en toda clase de estilos y gustos sin preocuparse del vecino, y no como en los tiempos remotos, cuando por no conocerse nuestra diversidad, todos los edificios armonizabanse. No basta en tal caso, dictar al arquitecto ordenanzas escritas, pues dentro de la rigidez de las normas, aparecerían los más extraños caprichos. Collins, Op. Cit., p. 193.

16 Collins, Op. Cit., p. 144.

17 Gibson, James Jerome (1974). La percepción del mundo visual. Infinito, Buenos Aires.

18 Rasmussen, Steen Eller (1951). Towns and buildings: described in drawings and words. The MIT Press, Cambridge, Mass.
19 Smith, G. E. Kidder (1955). Italy Builds: its modern architecture and native inheritance. Architectural Press, Londres.

20 Lynch, Kevin (1966). La imagen de la ciudad. Infinito, Buenos Aires.

21 Jacobs, Jane (1967). Muerte y vida de las grandes ciudades. Península, Madrid.

22 Hall, Edward T. (1972). La dimensión oculta. Siglo Veintiuno, México.

23 Bacon, Edmund (1967). Design of Cities. Thames and Hudson, Londres.

24 Benjamin, Walter (1998). Poesía y capitalismo. Taurus, Madrid. Pág. 183.

25 Benjamin, Op. Cit., p. 183.

26 Cohen, Jean-Louis; Staffan Ahrenberg (2013). Le Corbusier's Secret Laboratory: From Painting to Architecture. Hatje Cantz, Ostfildem. Pág. 66.

27 Una relación que ha sido analizada por Guy Davenport precisamente en las descripciones que Conan Doyle da de la residencia del número 221B de Baker Street en el caso de Holmes y del interior de la casa Usher en el caso de Poe. Davenport, Guy (2002). Objetos sobre una mesa: desorden armonioso en arte y literatura. Turner, Madrid.

28 Colomina, Beatriz (2006). Doble exposición: arquitectura a través del arte. Akal, Madrid.

29 TafuriI, Manfredo. Machine et mémoire: The City in the Work of Le Corbusier. En: Brooks, H. Allen (1987). Le Corbusier. Princeton University Press, Princeton.

30 Le Corbusier (1959). Mensaje a los estudiantes de arquitectura. Ediciones Infinito, Buenos Aires. Págs. 24-25

31 Rowe, Colin; Fred Koetter (1979). Ciudad Collage. Gustavo Gili, Barcelona.

32 Zizek, Slavoj (2012). Viviendo en el final de los tiempos. Akal, Madrid

33 Intervención de Aldo van Eyck en el CIAM de Otterlo de 1959. Risselada, Max; Dirk Van den Heuvel (2005). Team 10, 1953-81: In Search of a Utopia of the Present. NAi, Rotterdam.

34 Fernández-Llebrez, José (2013). La dimensión humana en la arquitectura de Aldo van Eyck. Escrita y construida: reconocimiento de sus ideas y estudio de su iglesia en La Haya. Tesis doctoral, Universidad Politécnica de Valencia, Escuela Técnica Superior de Arquitectura, Departamento de Construcciones Arquitectónicas, Valencia. 